Median (IOR) birth weight and gestational age were 3250g (2450$4300)$ and 38weeks (38-42) respectively. Fifty-eight percent of newborns were male. Rapidly rising of oxygen saturations and PI values after cardiac interventions were observed in all patients $\left(\mathrm{SaO}_{2} \%\right.$, before: $79 \pm 6.6$, after: $87.9 \pm 2.9, \mathrm{p}=0.001$ ) (PI before: $0.4 \pm 0.1$, after: $1.1 \pm 0.2, p=0.001)$. A significant decrease in NT-proBNP levels (pg/ $\mathrm{mL}$ ) were seen after therapeutic interventions too(before: $1547 \pm 629$, after: $911 \pm 262, \mathrm{p}=0.001)$. Six patients $(17.6 \%)$ required surgical intervention. The median (IOR) day of mechanical ventilation was 7 days (2-21). Proven sepsis $(n=8.23 \%)$, chronic lung disease $(n=5.14 \%)$, pulmonary hemorrhage $(n=4, \% 11)$, and pneumothorax $(n=3.8 \%)$ are the most detected complications. Mortality rate was $20 \%(n=5)$.

Conclusion Peripheral tissues are sensitive to alterations in perfusion. PI monitoring of these tissues could be an early marker of hypoperfusion. PI has significantly improved in correlation with $\mathrm{SpO} 2$ after therapeutic interventions. Assessment of PI and NTproBNP values could be used by monitoring peripheral tissues in critically ill newborns with CHD.

\section{RENAL IMPAIRMENT BY INDOMETHACIN FOR PDA IN VLBW INFANTS}

doi:10.1136/archdischild-2012-302724.1147

${ }^{1} Y$ J Kim, ' $\mathrm{JY}$ Lee, ${ }^{1} \mathrm{C}$ Kim, ${ }^{1} \mathrm{SH}$ Shin, 'SH Son, ${ }^{1} \mathrm{KY}$ Choi, ${ }^{2} \mathrm{JA}$ Lee, ${ }^{3} \mathrm{CW}$ Choi, 'EK Kim, ${ }^{1} \mathrm{HS}$ Kim, ${ }^{3} \mathrm{BI}$ Kim, ' $\mathrm{JH}$ Choi. 'Department of Neonatology, Department of Pediatrics, Seoul National University Children's Hospital; ${ }^{2}$ Department of Neonatology, Department of Pediatrics, Seoul National University Boramae Hospital; ${ }^{3}$ Department of Neonatology, Department of Pediatrics, Seoul National University Bundang Hospital, Seoul, Republic of Korea

The Aims of our study were to identify the risk factors of using indomethain to very low birth weight infants (VLBWIs) during treatment of PDA.

A retrospective review was undertaken of 95 VLBWIs who were born between January, 2008 and December, 2009, at Seoul National University Hospital NICU. Of the 158 infants, 103 infants were treated with indomethacin and 8 were excluded because one's mother had azotemia and 7 patients died within the first week of life. Patients were classified by renal insufficiency (RI) and normal renal function (NRF) group. RI group was defined as having oliguria or elevation of serum creatinine level over from $1^{\text {st }}$ dose of indomethacin administration until 2 days after finishing the course.

Fourty-nine infants were RI group and 46 were NRF group. Administration duration was longer $(2.5 \pm 2.0$ days vs. $1.5 \pm 1.1$ days, $\mathrm{p}=0.007)$ and number of dosages $(5.1 \pm 2.8$ days vs. $4.0 \pm 2.2$ days, $\mathrm{p}=0.048)$ and cumulative dose were higher in RI group $(0.85 \pm 0.52$ $\mathrm{mg} / \mathrm{kg}$ vs. $0.64 \pm 0.44 \mathrm{mg} / \mathrm{kg} \mathrm{p}=0.040$ ). Most of the clinical characters were not different between groups but dopamine administration rate $(28.6 \%$ vs. $8.7 \% ; p=0.013)$ and serum potassium level before administration of indomethacin $(6.1 \pm 1.5 \mathrm{mEq} / \mathrm{L}$ vs. $5.1 \pm 1.6 \mathrm{mEq} / \mathrm{L}$ $\mathrm{p}=0.005$ ) were significantly elevated in RI group.

Hyperkalemia before administrating indomethacin and frequency/ dose of indomethacin are related to occurrences of RI during indomethacin administration. Therefore, renal function monitoring and combined drugs which can influence the renal function should be monitored during treatment of PDA.

\section{A COMPARISON OF TWO STRATEGIES FOR THE MANAGEMENT OF PATENT DUCTUS ARTERIOSUS (PDA)}

doi:10.1136/archdischild-2012-302724.1148

A Paweletz, K Woodger, D Gardiner, N Subhedar. Neonatal Intensive Care Unit, Liverpool Women's Hospital, Liverpool, UK

Background and Aims The management of PDA in extremely preterm infants is controversial and there is no agreed optimal approach. Strategies that are commonly used include prophylactic, early asymptomatic or late symptomatic therapy. We describe our experience in changing from prophylactic indomethacin to late symptomatic treatment with ibuprofen.

Methods We collected data on all babies admitted $<28$ weeks' gestation and/or $<1000 \mathrm{~g}$ from an electronic patient database. We compared PDA diagnosis management, demographics and clinical outcomes in two six month time periods: period 1 was when we used a prophylaxis strategy with indomethacin and period 2 when we changed to late symptomatic treatment with ibuprofen.

Results

Abstract 1148 Table 1 Patient characteristics and clinical outcomes

\begin{tabular}{llll}
\hline & Period 1 & Period 2 & p \\
\hline $\mathrm{N}$ & 37 & 44 & \\
Birth weight $(\mathrm{g})$ & $875(710-940)$ & $820(706-940)$ & 0.08 \\
Gestation $(w k)$ & $26(25-27)$ & $26(25-27)$ & 0.85 \\
Symptomatic PDA & $1335 \%)$ & $19(43 \%)$ & 0.46 \\
Late treatment of PDA with IBU/IND & $6(16 \%)$ & $15(34 \%)$ & 0.07 \\
Duct ligation & $3(8 \%)$ & $1(2 \%)$ & 0.32 \\
Severe IVH (grade 3/4) & $6(16 \%)$ & $8(18 \%)$ & 1.0 \\
Chronic lung diease at 36 weeks PMA & $24(65 \%)$ & $26(60 \%)$ & 0.59 \\
Death & $11(31 \%)$ & $13(30 \%)$ & 0.92 \\
\hline
\end{tabular}

Conclusions Changing from a strategy of indomethacin prophylaxis to selective, late symptomatic treatment of PDA with ibuprofen did not result in a significant increase in babies with severe IVH, chronic lung diasease or those needing duct ligation.

\section{TREAT THE PDA? COMPARISON OF THE OUTCOME IN TREATED AND RESTRICTIVE TREATED VLBW INFANTS}

doi:10.1136/archdischild-2012-302724.1149

${ }^{1} \mathrm{~K}$ Linnemann, ${ }^{1} \mathrm{C}$ Kriegsmann, ${ }^{1} \mathrm{R}$ Stenger, ${ }^{2} \mathrm{C}$ Fusch, ${ }^{1} \mathrm{M}$ Heckmann. ${ }^{1}$ Neonatology and Pediatric Intensive Care Unit, University of Greifswald, Greifswald, Germany; ${ }^{2}$ Neonatology, Mc Master University, Hamilton, ON, Canada

Background Management of PDA is discussed controversial. In 2008 we changed our regime from restrictive treatment of PDA to treatment of PDA.

Aim Comparing the outcome of VLBW-Infants with two therapeutic PDA regimes: A restrictive treated and $B$ treated PDA.

Method Historical cohort- study of VLBW infants born between 2005 and 2007 (group A: n=120; treatment of PDA only if weight gain was inadequate $(<10 \mathrm{~g} / \mathrm{kg} / \mathrm{d}$ in spite of optimized nutrition) and between 2008 and 2010 (group B: $n=126$; treatment of "hemodynamic significant" PDA, diagnosed on the basis of reverse diastolic flow in the Truncus coeliacus or renal arteries < day 3). Other NICU guidelines were not changed but probiotics for NEC-prophylaxis started in 2011. Outcome measures: rate of NEC, BPD, IVH, neurological outcome (Laewen questionnaire).

Results In group A the rate of ductus closure was significantly lower than in group B (A: 19/53, B: 29/45; $\mathrm{p}<0.01)$. PDA rate in both groups did not differ significantly (A: 53/120; B: 45/126; $\mathrm{p}=0.67$ ). Surgical closure rate was $9 \%$ in both groups. The incidences of NEC, BPD and IVH were not different between groups. The results of the neurological outcome were not significantly different, but follow up reached only $60 \%$ so far.

Conclusions Changes in practice of PDA treatment in VLBW infants resulted in a $28 \%$ increase in frequency of medical or surgical closure of PDA without change in short or long term neonatal outcome. Further controlled randomized studies are needed to confirm our results on restrictive treatment of PDA.

1150 THE INCIDENCE AND RISK FACTORS OF THE CONGENITAL CARDIAC MALFORMATIONS IN NEWBORN

doi:10.1136/archdischild-2012-302724.1150 